\title{
Foot Pain and Pronated Foot Type Are Associated with Self-Reported Mobility Limitations in Older Adults: The Framingham Foot Study
}

\author{
Hylton B. Menz ${ }^{a} \quad$ Alyssa B. Dufour ${ }^{\text {b, c }}$ Patricia Katz ${ }^{d}$ Marian T. Hannan ${ }^{\text {b, c }}$ \\ a School of Allied Health, La Trobe University, Bundoora, Vic., Australia; 'b Institute for Aging Research, Hebrew \\ SeniorLife, and ${ }^{\mathrm{C}}$ Harvard Medical School, Boston, Mass., and ${ }^{\mathrm{d}}$ University of California, San Francisco, Calif., USA
}

\section{Key Words}

Aging · Mobility $\cdot$ Pain · Foot

\begin{abstract}
Background: The foot plays an important role in supporting the body when undertaking weight-bearing activities. Aging is associated with an increased prevalence of foot pain and a lowering of the arch of the foot, both of which may impair mobility. Objective: To examine the associations of foot pain, foot posture and dynamic foot function with self-reported mobility limitations in community-dwelling older adults. Methods: Foot examinations were conducted on 1,860 members of the Framingham Study in 2002-2005. Foot posture was categorized as normal, planus or cavus using static pressure measurements, and foot function was categorized as normal, pronated or supinated using dynamic pressure measurements. Participants were asked whether they had foot pain and any difficulty performing a list of eight weight-bearing tasks. Multivariate logistic regression and linear regression models were used to examine the associations of foot pain, posture, function and ability to perform these activities. Results: After adjusting for age, sex, height and weight, foot pain was significantly associated with difficulty performing all eight weight-bearing activities. Compared to those with normal foot posture and function, participants with planus foot posture were more likely to report difficulty remaining balanced [odds ratio $(O R)=1.40$,
\end{abstract}

95\% confidence interval $(\mathrm{Cl}) 1.06-1.85 ; \mathrm{p}=0.018$ ] and individuals with pronated foot function were more likely to report difficulty walking across a small room $(O R=2.07,95 \%$ $\mathrm{Cl} 1.02-4.22 ; \mathrm{p}=0.045)$. Foot pain and planus foot posture were associated with an overall mobility limitation score combining performances on each measure. Conclusion: Foot pain, planus foot posture and pronated foot function are associated with self-reported difficulty undertaking common weight-bearing tasks. Interventions to reduce foot pain and improve foot posture and function may therefore have a role in improving mobility in older adults.

(c) 2015 S. Karger AG, Base

\section{Introduction}

The foot plays an important role in maintaining balance when undertaking weight-bearing tasks and generating momentum during walking. Consequently, any disruption to the load-bearing function of the foot has the potential to impair functional ability in older adults. Indeed, foot pain, which affects approximately 1 in 4 older adults [1], has been shown to be associated with both selfreported [2-4] and objectively measured mobility limitation $[3,5,6]$ and is an independent risk factor for accidental falls $[7,8]$. Mobility impairment associated with foot pain is common and has a substantial detrimental impact on health-related quality of life in this age group [4, 9].

\section{KARGER}

E-Mail karger@karger.com

www.karger.com/ger (c) 2015 S. Karger AG, Basel

0304-324X/15/0623-0289\$39.50/0
Prof. Hylton B. Menz

School of Allied Health

La Trobe University

Bundoora, VIC 3086 (Australia)

E-Mail h.menz@latrobe.edu.au 
In addition to foot pain, age-related changes to the structure and function of the foot have the potential to impair mobility in older people. With advancing age, the foot exhibits increased soft-tissue stiffness, decreased range of motion and strength and adopts a more pronated posture when standing and walking [10]. In both young [11-13] and older [14] people, pronated foot posture has been shown to impair standing balance. However, no studies have examined whether the dynamic function of the foot influences mobility in older people. This is an important issue to address for two reasons. First, because the association between foot posture and dynamic foot function is only modest [15], static measures of foot posture may not fully explain the contribution of the foot to the performance of mobility tasks. Second, because dynamic foot function can be modified with footwear and orthoses [16], there may be some scope for improving mobility in older adults with appropriately targeted interventions.

Therefore, the objective of this study was to examine the effect of foot pain, foot posture and dynamic foot function on self-reported mobility limitations in older adults who took part in the Framingham Foot Study (FFS). We hypothesized that in addition to foot pain, planus foot posture and pronated foot function would be associated with impaired performance in a range of selfreported mobility tasks.

\section{Methods}

\section{Participants}

The FFS cohort was derived from members of the Framingham Study Original Cohort, the Framingham Offspring Cohort and a third community sample. The Framingham Study Original Cohort was formed in 1948 from a two-thirds sample $(n=5,209)$ of the town of Framingham, Mass., USA, in order to study risk factors for heart disease [17]. This cohort has been followed biennially since that time. The Framingham Offspring Cohort, formed in 1972, consists of adult offspring who had a parent in the Framingham Original Cohort, and the spouses of the offspring $(n=5,124)$ [18]. This group has been followed every 4 years since cohort inception to study familial risk factors for heart disease. The community sample was derived from census-based, random-digit dialling within the Framingham community by the Center for Survey Research at the University of Massachusetts, selecting subjects who were 50 years old and ambulatory in order to increase participation by minority persons and other community members of the Framingham catchment area (using a targeted random-digit dialling schema in selected Framingham census tracts). Participants from these cohorts were invited to participate in the FFS between 2002 and 2005. Of these, FFS data (physical examination of the foot with accompanying questionnaire) were collected from 266 Original, 981 Offspring and 982 community cohort members at either the scheduled or call-back Framingham clinic examination. Partici- pants who had complete FFS data (including information on foot pain), self-reported mobility measures and covariates were included in this analysis. The FFS was approved by the institutional review board at Hebrew SeniorLife, and informed consent was obtained from all participants.

\section{Assessment of Foot Pain}

All participants were ambulatory and cognitively intact (as indicated by a Mini-Mental State Examination score $>24$ [19]), so that we could identify study subjects who would be able to give symptom information about their feet. Generalized foot pain was determined using the following National Health and Nutrition Examination Survey-based query about foot pain: 'On most days, do you have pain, aching, or stiffness in either of your feet?' Possible responses were no; yes, left foot only; yes, right foot only; yes, both feet; yes, not sure what side, and unknown. For this analysis, responses were collapsed into 2 groups: (i) yes, pain in one or both feet, or (ii) no, no pain in either foot.

\section{Assessment of Foot Posture and Function}

Foot posture and function were both assessed using the Tekscan ${ }^{\circledR}$ MatScan ${ }^{\circledR}$ system (Tekscan, Inc., Boston, Mass., USA). The system consists of a 5 -mm-thick floor mat $(432 \times 368 \mathrm{~mm})$, comprising 2,288 resistive sensors $\left(1.4\right.$ sensors $\left./ \mathrm{cm}^{2}\right)$ and sampling data at a frequency of $40 \mathrm{~Hz}$. The reliability of this system has been described in detail previously [20]. Two types of scans were collected: standing and walking. For the standing scan, a one-frame self-selected bipedal stance 'snap shot' image was collected for each participant. For the walking scans, participants walked across the mat at a self-selected pace using the two-step method, which involves striking the platform on the second step. One walking trial of each foot was recorded.

Foot posture was assessed using the arch index (AI), which was first described by Cavanagh and Rogers [21]. From the maximum peak pressure image of the participants' bipedal relaxed stance, the AI was calculated as the ratio of the area of the middle third of the footprint to the entire footprint area (excluding the toes), with a higher value representing a flatter foot. AI scores have previously been shown to be highly correlated with navicular height [22] and angular medial longitudinal arch measures $[22,23]$ obtained from foot radiographs. AI scores were divided into quintiles for men and women separately, and foot posture was categorized as cavus (those in the lowest 20\%), normal (those in the middle 60\%) or planus (those in the highest 20\%). The cutoff scores to define each category were as follows: cavus $(0-0.134)$, normal $(0.135-0.272)$ and planus $(0.273-0.565)$ for men, and cavus $(0-0.119)$, normal $(0.120-0.261)$ and planus (0.262-0.534) for women [24].

Foot function was assessed by calculating the center of pressure excursion index (CPEI) of the walking trials. The CPEI represents the degree of mediolateral deviation of the center of pressure at the anterior one third trisection of the foot, relative to a line connecting the first and last center of pressure data points, and is described in detail elsewhere [25]. In a pronated foot, the concavity of the center of pressure curve is decreased, resulting in a smaller CPEI value. In a supinated foot, the concavity of the center of pressure curve is increased, resulting in a larger CPEI value. The CPEI has previously been shown to demonstrate excellent intra- and intertester reliability (intra-class correlation coefficients of 0.97 and 0.98, respectively) [25]. As with AI scores, CPEI scores were then divided into quintiles, and participants were categorized as having 
supinated foot function (those in the highest 20\%), normal foot function (those in the middle 60\%) or pronated foot function (those in the lowest 20\%). The cutoff scores to define each category were as follows: supinated (22.5-43.7), normal (9.4-22.4) and pronated (-25.3-9.3) [24].

Typical examples of cavus, normal and planus foot posture as well as supinated, normal and pronated foot function categories using this classification system are shown in figure 1 .

\section{Self-Reported Mobility Limitations}

Self-reported mobility limitation was determined by asking participants whether they experienced any difficulty undertaking eight weight-bearing activities: remaining balanced while standing, standing for $\geq 15 \mathrm{~min}$, getting in and out of a car, getting in and out of bed, getting in and out of a chair, walking two to three blocks, walking across a small room and walking up and down a flight of stairs $[26,27]$. The response options were: no difficulty, a little difficulty, some difficulty, a lot of difficulty, or unable to do. Participants were considered to be limited in each activity if they reported at least a little difficulty performing the task. An overall mobility limitation score was also calculated by summing the dichotomized responses to these eight items (i.e. score range from 0 to 8 ).

\section{Covariates}

Covariates in our analyses included age, sex, height and weight. Age in years at the time of examination was recorded. Height (without shoes) was measured using a calibrated stadiometer and recorded to the nearest one-quarter inch. Weight was measured using a standardized balance beam and recorded to the nearest half pound. Height and weight measures were used to determine the body mass index.

\section{Statistical Analysis}

Multivariable logistic regression models were used to calculate odds ratios (ORs) and 95\% confidence intervals (CIs) for the association between foot pain, foot posture, foot function and selfreported mobility limitation for each activity, adjusting for age, sex, height and weight. Linear regression was used to examine associations between foot pain, foot posture, foot function and the self-reported and overall mobility limitation score. All analyses were conducted using the SAS statistical analysis package, version 9.1 (SAS Institute, Cary, N.C., USA).

\section{Results}

Of the 2,229 participants in the FFS, 1,860 participants (830 men and 1,030 women) had complete foot pain, posture, function and self-reported mobility limitation data. The mean age of the participants was 65 years, and women comprised $55 \%$ of the sample population. Foot pain, aching or stiffness in either of their feet on most days was reported by 497 (27\%) participants. Mobility limitation in at least one activity was reported by 1,107 (60\%) of participants and increased with age (table 1).

Associations between foot pain, posture, function and self-reported mobility limitations are shown in table 2.

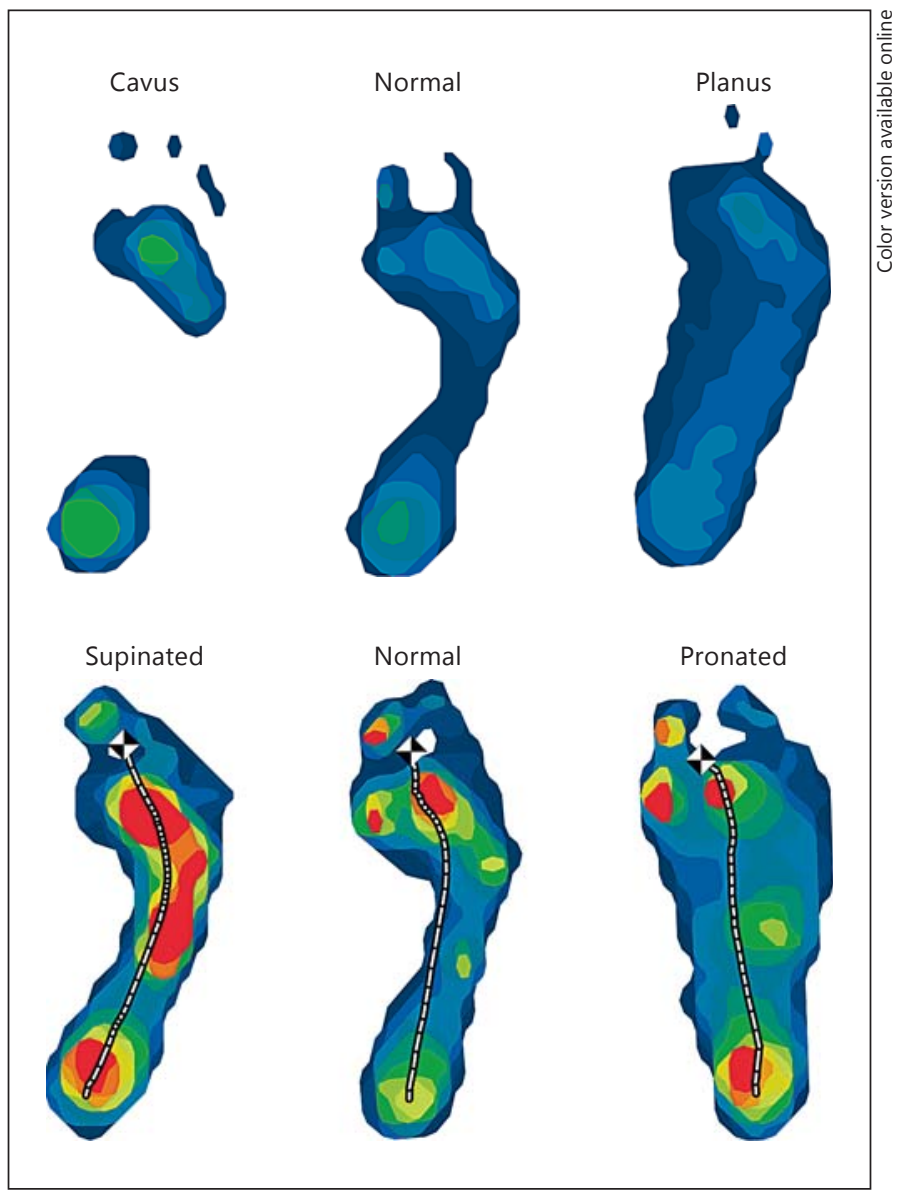

Fig. 1. Typical examples of cavus, normal and planus static foot posture categories (top) as well as supinated, normal and pronated dynamic foot function categories (bottom). Reproduced with permission from [24].

After adjusting for age, sex, height and weight, foot pain was significantly associated with difficulty performing all eight weight-bearing activities, with ORs ranging from 1.81 to 3.45 . Compared to those with normal foot posture and function, individuals with planus foot posture were more likely to report difficulty remaining balanced $(\mathrm{OR}=1.40,95 \%$ CI 1.06-1.85; $\mathrm{p}=0.018)$ and individuals with pronated foot function were more likely to report difficulty walking across a small room $(\mathrm{OR}=2.07,95 \% \mathrm{CI}$ 1.02-4.22; $\mathrm{p}=0.045)$.

Results of the linear regressions are shown in table 3. After adjusting for age, sex, height and weight, foot pain was significantly associated with the overall mobility limitation score (least squares mean $=2.71 ; \mathrm{p}<0.001$ ), as was planus foot posture (least squares mean $=1.95$; $\mathrm{p}=0.038)$. 
Table 1. Characteristics of participants in the FFS (2002-2005) with completed foot examination and self-reported mobility limitation data

\begin{tabular}{lc}
\hline Age, years & $65.4 \pm 10.6$ \\
Females & $1,030(55)$ \\
Height, cm & $167.6 \pm 26.9$ \\
Weight, kg & $78.9 \pm 17.8$ \\
Body mass index & $28.35 \pm 5.49$ \\
Foot pain & $497(26.7)$ \\
\hline Self-reported mobility limitations & \\
Difficulty with at least one task & $1,107(60)^{\mathrm{a}}$ \\
Aged $<50$ years & $15(37)$ \\
Aged 50-60 years & $309(52)$ \\
Aged 60-70 years & $373(57)$ \\
Aged 70-80 years & $237(65)$ \\
Aged 80-90 years & $154(78)$ \\
Aged $>90$ years & $19(90)$ \\
Difficulty with individual tasks & \\
Remaining balanced while standing & $389(21)$ \\
Standing in one place $\geq 15$ min & $674(36)$ \\
Getting in and out of a car & $593(32)$ \\
Getting in and out of bed & $406(22)$ \\
Getting in and out of a chair & $379(20)$ \\
Walking 2-3 blocks & $361(19)$ \\
Walking across a small room & $44(2)$ \\
Walking up or down a flight of stairs & $568(31)$ \\
Overall score & $1.84(2.2)$ \\
\hline
\end{tabular}

Values are shown as $\mathrm{n}(\%)$ or mean $\pm \mathrm{SD}$. ${ }^{\text {a }}$ Total sample.

\section{Discussion}

The objective of this study was to evaluate the independent relationships between foot pain, foot posture and dynamic foot function with self-reported mobility limitations in a population of community-dwelling older adults who participated in the FFS (2002-2005). Our findings indicate that foot pain was independently associated with self-reported difficulty performing all eight activities, and an overall mobility limitation score combining performances on each individual measure. In addition, older people with planus foot posture were more likely to report difficulty remaining balanced, and those with pronated foot function were more likely to report difficulty walking across a small room. Planus foot posture was also associated with the overall mobility limitation score.

The associations we observed between foot pain and self-reported mobility limitation are consistent with previous studies reporting significant associations between foot symptoms and a range of self-reported measures of mobility, including walking difficulty [28], instrumental activities of daily living [3], the physical function and role-physical subscales of the Short Form 36 questionnaire [4] and the Stanford Health Assessment Questionnaire disability index [5]. A fundamental requirement of each of the activities included in our mobility measure is the ability to support and transfer body weight, which invariably places mechanical demands on the foot. In the presence of foot pain, this support function may be compromised, resulting in impaired performance. Evidence to support this proposed mechanism can be derived from studies of experimentally induced foot pain, which have noted gait alterations [29] and increased postural sway [30] when a noxious stimulus is applied to the plantar surface of the foot.

Our finding of an association between planus foot posture and self-reported difficulty remaining balanced builds on previous work exploring the effect of foot posture on postural stability. In young adults, Cobb et al. [11] reported that those with forefoot varus exhibited greater anteroposterior postural sway in single-limb stance, which they attributed to decreased joint congruity associated with the planus foot. Similarly, Tsai et al. [12] reported that young adults with planus feet demonstrated greater anteroposterior postural sway in single-limb stance and were able to maintain balance for a shorter duration than those with neutral feet, and Tahmasebi et al. [13] found that sway velocity in young adults was greater in those with flat feet according to AI measurements. In older adults, Spink et al. [14] found that planus foot posture was associated with poorer performance on a test of postural sway. Taken together, these findings support the view that the ability to maintain balance is compromised in individuals with planus feet, possibly as a result of this foot type being inherently more mobile when standing compared to the neutral or cavus foot type [31]. Interestingly, however, foot posture was not associated with the remaining mobility tasks, possibly because they mostly reflect more dynamic, gait-related activities, and the relationship between foot posture and dynamic function is less clear [15].

The most novel aspect of our study is the inclusion of a measure of dynamic foot function, the CPEI. This measure is derived from a dynamic foot pressure recording and represents the degree of mediolateral deviation of the center of pressure at the anterior third trisection of the foot when walking [25]. We hypothesized that pronated foot function according to the CPEI would be associated with self-reported mobility limitations. This was evident for one task: walking across a small room. A possible explanation for the lack of association between dynamic foot function and the remaining mobility tasks is that we 
Table 2. Associations of foot pain, posture and function with self-reported mobility limitations in the FFS (2002-2005), adjusted for age, sex, height and weight

\begin{tabular}{|c|c|c|c|}
\hline & & OR $(95 \% \mathrm{CI})$ & $\mathrm{p}$ \\
\hline \multicolumn{4}{|c|}{ Remaining balanced } \\
\hline Foot pain & & $2.60(2.03-3.34)$ & $<0.001$ \\
\hline \multirow[t]{2}{*}{ Foot posture } & Cavus vs. normal & $1.14(0.84-1.54)$ & 0.406 \\
\hline & Planus vs. normal & $1.40(1.06-1.85)$ & 0.018 \\
\hline \multirow[t]{2}{*}{ Foot function } & Supinated vs. normal & $0.91(0.67-1.23)$ & 0.540 \\
\hline & Pronated vs. normal & $1.10(0.84-1.45)$ & 0.470 \\
\hline \multicolumn{4}{|c|}{ Standing in one place $\geq 15$ min } \\
\hline Foot pain & & $2.26(1.82-2.82)$ & $<0.001$ \\
\hline \multirow[t]{2}{*}{ Foot posture } & Cavus vs. normal & $1.11(0.87-1.43)$ & 0.398 \\
\hline & Planus vs. normal & $1.09(0.86-1.39)$ & 0.469 \\
\hline \multirow[t]{2}{*}{ Foot function } & Supinated vs. normal & $1.19(0.93-1.52)$ & 0.160 \\
\hline & Pronated vs. normal & $1.03(0.81-1.30)$ & 0.822 \\
\hline \multicolumn{4}{|c|}{ Getting in and out of a car } \\
\hline Foot pain & & $2.25(1.80-2.82)$ & $<0.001$ \\
\hline \multirow[t]{2}{*}{ Foot posture } & Cavus vs. normal & $1.25(0.97-1.62)$ & 0.088 \\
\hline & Planus vs. normal & $1.13(0.88-1.44)$ & 0.350 \\
\hline \multirow[t]{2}{*}{ Foot function } & Supinated vs. normal & $1.00(0.78-1.30)$ & 0.974 \\
\hline & Pronated vs. normal & $1.00(0.79-1.27)$ & 0.977 \\
\hline \multicolumn{4}{|c|}{ Getting in and out of bed } \\
\hline Foot pain & & $2.38(1.88-3.02)$ & $<0.001$ \\
\hline \multirow[t]{2}{*}{ Foot posture } & Cavus vs. normal & $0.91(0.68-1.23)$ & 0.547 \\
\hline & Planus vs. normal & $1.03(0.78-1.34)$ & 0.852 \\
\hline \multirow[t]{2}{*}{ Foot function } & Supinated vs. normal & $1.03(0.78-1.37)$ & 0.839 \\
\hline & Pronated vs. normal & $1.09(0.84-1.42)$ & 0.513 \\
\hline \multicolumn{4}{|c|}{ Getting in and out of a chair } \\
\hline Foot pain & & $2.17(1.70-2.88)$ & $<0.001$ \\
\hline \multirow[t]{2}{*}{ Foot posture } & Cavus vs. normal & $1.21(0.89-1.65)$ & 0.998 \\
\hline & Planus vs. normal & $1.08(0.82-1.42)$ & 0.459 \\
\hline \multirow[t]{2}{*}{ Foot function } & Supinated vs. normal & $1.05(0.79-1.41)$ & 0.727 \\
\hline & Pronated vs. normal & $0.88(0.67-1.15)$ & 0.345 \\
\hline \multicolumn{4}{|c|}{ Walking 2-3 blocks } \\
\hline Foot pain & & $2.96(2.27-3.85)$ & $<0.001$ \\
\hline \multirow[t]{2}{*}{ Foot posture } & Cavus vs. normal & $0.86(0.62-1.20)$ & 0.377 \\
\hline & Planus vs. normal & $1.05(0.78-1.40)$ & 0.765 \\
\hline \multirow[t]{2}{*}{ Foot function } & Supinated vs. normal & $0.92(0.67-1.26)$ & 0.592 \\
\hline & Pronated vs. normal & $1.09(0.82-1.44)$ & 0.564 \\
\hline \multicolumn{4}{|c|}{ Walking across a small room } \\
\hline Foot pain & & $3.45(1.84-6.48)$ & $<0.001$ \\
\hline \multirow[t]{2}{*}{ Foot posture } & Cavus vs. normal & $0.52(0.19-1.43)$ & 0.205 \\
\hline & Planus vs. normal & $0.82(0.41-1.65)$ & 0.570 \\
\hline \multirow[t]{2}{*}{ Foot function } & Supinated vs. normal & $1.22(0.51-2.93)$ & 0.652 \\
\hline & Pronated vs. normal & $2.07(1.02-4.22)$ & 0.045 \\
\hline \multicolumn{4}{|c|}{ Difficulty walking up or down a flight of stairs } \\
\hline Foot pain & & $2.39(1.90-3.01)$ & $<0.001$ \\
\hline \multirow[t]{2}{*}{ Foot posture } & Cavus vs. normal & $0.87(0.66-1.14)$ & 0.305 \\
\hline & Planus vs. normal & $1.11(0.86-1.42)$ & 0.420 \\
\hline Foot function & Supinated vs. normal & $1.10(0.84-1.43)$ & 0.493 \\
\hline & Pronated vs. normal & $1.01(0.79-1.29)$ & 0.968 \\
\hline
\end{tabular}


Table 3. Least squares means and $p$ values from a linear regression between the overall mobility limitations score and foot pain, foot posture and foot function, adjusted for age, sex, height and weight

\begin{tabular}{lll}
\hline & Least squares means & $\mathrm{p}$ \\
\hline $\begin{array}{l}\text { Foot pain } \\
\text { No }\end{array}$ & & \\
$\quad$ Yes & 1.52 & - \\
\hline $\begin{array}{l}\text { Foot posture } \\
\text { Referent }\end{array}$ & 2.71 & $<0.001$ \\
$\quad$ Cavus & 1.72 & - \\
$\quad$ Planus & 1.88 & 0.212 \\
\hline Foot function & 1.95 & 0.038 \\
$\quad$ Referent & 1.81 & \\
$\quad$ Supinated & 1.85 & - \\
$\quad$ Pronated & 1.85 & 0.700 \\
\hline
\end{tabular}

calculated the CPEI from a platform-based plantar pressure system while participants were barefoot, rather than using an in-shoe system while participants were shod. Variations in footwear may affect both mobility [32] and dynamic foot function [33] compared to being barefoot, so it is likely that footwear confounded the association between dynamic foot function and mobility limitations. While it is true that the foot posture measures were also performed barefoot, it is possible that footwear has a greater influence on dynamic foot function than its static skeletal alignment.

Clinically, these findings suggest that interventions to reduce foot pain and improve foot posture and function may have a role in improving mobility in older adults. Such interventions could include physical therapy, orthoses and footwear. Several studies have shown that foot orthoses which support the arch can reduce pain $[34,35]$ and improve balance [34, 36-38] in older people, and a recent randomized trial reported that extra-depth footwear was effective at reducing foot pain and improving foot function [39]. In addition, a multifaceted podiatry intervention consisting of regular lesion debridement, foot and ankle exercises, foot orthoses and footwear has been shown to reduce the incidence of falling by $36 \%$ [40]. Further trials with longer duration of follow-up are required to determine whether these interventions have beneficial effects on broader aspects of physical function in older people.

Strengths of this study include the large populationbased sample, objective measures of foot posture and dynamic foot function, and statistical adjustment for several potential confounding variables. However, our findings need to be interpreted in the context of several limitations. First, although our findings suggest that foot pain, foot posture and foot function are associated with mobility limitations, we acknowledge that there are many other factors that may also contribute. Second, we did not attempt to characterize the type of foot pain reported by participants, so it is possible that different types of pain (e.g. nociceptive or neuropathic) may have had differential effects on physical function. Third, the CPEI has yet to be validated against a multi-segment kinematic foot model. Fourth, the Framingham population is largely Caucasian. Given that there are significant racial differences in foot structure [41], different patterns of association may be evident in more diverse populations. Finally, the key limitation of all cross-sectional studies is the inability to confidently infer causation, although we consider reverse causation to be a less plausible explanation of the observed associations.

\section{Conclusion}

Foot pain, planus foot posture and pronated foot function are associated with self-reported difficulty undertaking common weight-bearing tasks in older adults. Interventions to reduce foot pain and improve foot posture and function, such as foot orthoses and footwear, may therefore have a role in optimizing mobility in this age group.

\section{Acknowledgements}

The authors acknowledge the FFS research team and study participants for the contribution of their time, effort and dedication. Funding for this project was provided by the National Institute of Arthritis and Musculoskeletal and Skin Diseases and the National Institute on Aging (AR047853). This work was derived from the Framingham Heart Study of the National Heart Lung and Blood Institute of the National Institutes of Health and Boston University School of Medicine. This work was supported by the National Heart, Lung and Blood Institute's Framingham Heart Study (Contract No. N01-HC-25195). H.B.M. is a National Health and Medical Research Council fellow (ID: 433049) and was supported by an Australian-American Fulbright Commission Senior Scholarship when this work was undertaken. The National Institutes of Health played no role in the design or conduct of the study; the collection, management, analysis or interpretation of the data; or the preparation, review, or approval of the manuscript.

\section{Disclosure Statement}

The authors have no conflicts of interest to report. 


\section{References}

$>_{1}$ Thomas M, Roddy E, Zhang W, Menz H, $>14$ Spink MJ, Fotoohabadi MR, Wee E, Hill KD, Hannan M, Peat G: The population prevalence of foot and ankle pain in middle and old age: a systematic review. Pain 2011;152:28702880 .

-2 Leveille SG, Guralnik JM, Ferrucci L, Hirsch $\mathrm{R}$, Simonsick E, Hochberg MC: Foot pain and disability in older women. Am J Epidemiol 1998;148:657-665.

-3 Benvenuti F, Ferrucci L, Guralnik JM, Gangemi S, Baroni A: Foot pain and disability in older persons: an epidemiologic survey. J Am Geriatr Soc 1995;43:479-484.

4 Mickle KJ, Munro BJ, Lord SR, Menz HB, Steele JR: Cross-sectional analysis of foot function, functional ability, and health-related quality of life in older people with disabling foot pain. Arthritis Care Res (Hoboken) 2011; 63:1592-1598.

$>5$ Golightly YM, Hannan MT, Shi XA, Helmick CG, Renner JB, Jordan JM: Association of foot symptoms with self-reported and performance-based measures of physical function: the Johnston County osteoarthritis project. Arthritis Care Res (Hoboken) 2011;63:654659.

6 Menz HB, Dufour AB, Casey VA, Riskowski JL, McLean RR, Katz P, Hannan MT: Foot pain and mobility limitations in older adults: the Framingham Foot Study. J Gerontol A Biol Sci Med Sci 2013;68:1281-1285.

7 Leveille SG, Bean J, Bandeen-Roche K, Jones R, Hochberg M, Guralnik JM: Musculoskeletal pain and risk of falls in older disabled women living in the community. J Am Geriatr Soc 2002;50:671-678.

$\checkmark 8$ Menz HB, Morris ME, Lord SR: Foot and ankle risk factors for falls in older people: a prospective study. J Gerontol A Biol Sci Med Sci 2006;61:866-870

-9 Menz HB, Tiedemann A, Kwan MMS, Plumb $\mathrm{K}$, Lord SR: Foot pain in community-dwelling older people: an evaluation of the Manchester Foot Pain and Disability Index. Rheumatology $2006 ; 45: 863-867$.

$>10$ Menz HB: Biomechanics of the ageing foot and ankle: a mini-review. Gerontology 2015; 61:381-388.

11 Cobb SC, Tis LL, Johnson BF, Higbie EJ: The effect of forefoot varus on postural stability. J Orthop Sports Phys Ther 2004;34:79-85.

-12 Tsai LC, Yu B, Mercer VS, Gross MT: Comparison of different structural foot types for measures of standing postural control. J Orthop Sports Phys Ther 2006;36:942-953.

13 Tahmasebi R, Karimi MT, Satvati B, Fatoye F: Evaluation of standing stability in individuals with flatfeet. Foot Ankle Spec 2015;8:168174. Lord SR, Menz HB: Foot and ankle strength, range of motion, posture, and deformity are associated with balance and functional ability in older adults. Arch Phys Med Rehabil 2011; 92:68-75.

15 Buldt AK, Murley GS, Butterworth P, Levinger P, Menz HB, Landorf KB: The relationship between foot posture and lower limb kinematics during walking: a systematic review. Gait Posture 2013;38:363-372.

16 Cheung RT, Chung RC, Ng GY: Efficacies of different external controls for excessive foot pronation: a meta-analysis. Br J Sports Med 2011;45:743-751.

17 Dawber T, Meadors G, Moore F: Epidemiological approaches to heart disease: the Framingham Study. Am J Public Health Nations Health 1951;41:279-281.

18 Feinleib M, Kannel W, Garrison R, McNamara $\mathrm{P}$, Castelli W: The Framingham Offspring Study: design and preliminary data. Prev Med 1975;4:518-525.

19 Folstein MF, Folstein SE, McHugh PR: 'Minimental state'. A practical method for grading the cognitive state of patients for the clinician. J Psychiatr Res 1975;12:189-198.

20 Zammit GV, Menz HB, Munteanu SE: Reliability of the TekScan MatScan(R) system for the measurement of plantar forces and pressures during barefoot level walking in healthy adults. J Foot Ankle Res 2010;3:11.

21 Cavanagh PR, Rodgers MM: The arch index: a useful measure from footprints. J Biomech 1987;20:547-551.

22 Menz HB, Munteanu SE: Validity of 3 clinical techniques for the measurement of static foot posture in older people. J Orthop Sports Phys Ther 2005;35:479-486.

23 Murley GS, Menz HB, Landorf KB: A protocol for classifying normal- and flat-arched foot posture for research studies using clinical and radiographic measurements. J Foot Ankle Res 2009;2:22.

24 Menz HB, Dufour AB, Riskowski JL, Hillstrom HJ, Hannan MT: Association of planus foot posture and pronated foot function with foot pain: the Framingham foot study. Arthritis Care Res (Hoboken) 2013;65:1991-1999.

25 Song J, Hillstrom HJ, Secord D, Levitt J: Foot type biomechanics: a comparison of planus and rectus foot types. J Am Podiatr Med Assoc 1996;86:16-23.

26 Rosow I, Breslau H: A Guttman health scale for the aged. J Gerontol 1966;21:556-559.

27 Jette A, Branch L: The Framingham Disability Study. II. Physical disability among the aging. Am J Public Health 1981;71:1211-1216.

-28 Gorter KJ, Kuyvenhoven MM, de Melker RA: Nontraumatic foot complaints in older people. A population-based survey of risk factors, mobility, and well-being. J Am Podiatr Med Assoc 2000;90:397-402.
29 Levins A, Skinner H, Caiozzo V: Adaptive gait responses to plantar heel pain. J Rehabil Res Dev 1998;35:289-293.

30 Pradels A, Pradon D, Vuillerme N: Effects of experimentally induced pain of the plantar soles on centre of foot pressure displacements during unperturbed upright stance. Clin Biomech 2011;26:424-428.

31 Cornwall MW, McPoil TG: Relationship between static foot posture and foot mobility. J Foot Ankle Res 2011;4:4.

32 Menant JC, Steele JR, Menz HB, Munro BJ, Lord SR: Optimizing footwear for older people at risk of falls. J Rehabil Res Dev 2008;45: 1167-1181.

33 Xu H, Akai M, Kakurai S, Yokota K, Kaneko $\mathrm{H}$ : Effect of shoe modifications on center of pressure and in-shoe plantar pressures. Am J Phys Med Rehabil 1999;78:516-524.

34 Mulford D, Taggart HM, Nivens A, Payrie C: Arch support use for improving balance and reducing pain in older adults. Appl Nurs Res 2008;21:153-158.

35 Chang B-C, Liu D-H, Chang JL, Lee S-H, Wang J-Y: Plantar pressure analysis of accommodative insole in older people with metatarsalgia. Gait Posture 2014;39:449-454.

36 Gross MT, Mercer VS, Lin FC: Effects of foot orthoses on balance in older adults. J Orthop Sports Phys Ther 2012;42:649-657.

37 de Morais Barbosa C, Barros Bertolo M, Marques Neto JF, Bellini Coimbra I, Davitt M, de Paiva Magalhaes E: The effect of foot orthoses on balance, foot pain and disability in elderly women with osteoporosis: a randomized clinical trial. Rheumatology 2013;52: 515-522.

38 Chen TH, Chou LW, Tsai MW, Lo MJ, Kao MJ: Effectiveness of a heel cup with an arch support insole on the standing balance of the elderly. Clin Interv Aging 2014;9:351-356.

39 Menz HB, Auhl M, Ristevski S, Frescos N, Munteanu SE: Effectiveness of off-the-shelf, extra-depth footwear in reducing foot pain in older people: a randomized controlled trial. J Gerontol A Biol Sci Med Sci 2015;70:511517.

40 Spink MJ, Menz HB, Fotoohabadi MR, Wee E, Landorf KB, Hill KD, Lord SR: Effectiveness of a multifaceted podiatry intervention to prevent falls in community dwelling older people with disabling foot pain: randomised controlled trial. BMJ 2011;342:d3411.

41 Golightly YM, Hannan MT, Dufour AB, Jordan JM: Racial differences in foot disorders and foot type. Arthritis Care Res (Hoboken) 2012;64:1756-1759. 